\title{
DESARROLLO DE LA AUTORREGULACIÓN DEL APRENDIZAJE EN EDUCACIÓN SECUNDARIA Y MEDIA SUPERIOR ANTE LA CONTINGENCIA DE LA COVID-19
}

\author{
DEVELOPMENT OF SELF-REGULATION OF \\ LEARNING IN MIDDLE AND HIGH SCHOOL \\ EDUCATION IN THE FACE OF \\ THE COVID-19 CONTINGENCY
}

Javier Fernández-de-Castro ${ }^{1}$

https:// orcid.org/0000-0002-7552-5560

Leticia Nayeli Ramírez-Ramírez ${ }^{2}$

https://orcid.org/0000-0002-8113-2368

Luz María Rojas-Muñoz

Recibido: agosto 7, 2020 - Aceptado: octubre 19, 2020

\section{RESUMEN}

Ante la declaración oficial de la COVID-19 como pandemia, por parte de la Organización Mundial de la Salud, en México se declaró en marzo de 2020, la suspensión de actividades presenciales en los plateles educativos a través de un Acuerdo promulgado en el Diario Oficial de la Federación. Dicha suspensión se prolongó hasta la finalización del ciclo escolar, provocando que estudiantes, profesores y directivos tuvieran que implementar una modalidad a distancia a fin de dar continuidad al proceso formativo. El presente estudio persigue el objetivo de determinar si el grado de autorregulación del aprendizaje de estudiantes de educación secundaria y media superior sufrió alguna modificación significativa ante este cambio de modalidad. Para ello se desarrolló un estudio no experimental, longitudinal, con alcance exploratorio y descriptivo. Se trabajó con una muestra de 206 estudiantes de

1 Doctor en Educación, «Medida y Evaluación de la Intervención Educativa», Universidad Anáhuac, México Norte. Secretario de investigación de la Escuela de Pedagogía, Universidad Panamericana, Aguascalientes. jfernandezc@up.edu.mx

2 Doctora en Psicología Educativa y del Desarrollo, Universidad Nacional Autónoma de México. Profesora investigadora de la Escuela de Pedagogía, Universidad Panamericana, Aguascalientes. Miembro del Sistema Nacional de Investigadores del Conacyt, México (Nivel Candidato). Miembro del Consejo Mexicano de Investigación Educativa (COMIE). nramirez@up.edu.mx

Ingeniera Bioquímica, Universidad Autónoma de Aguascalientes, México. Coordinadora de Ciencias de secundaria y bachillerato, Cumbres International School de Aguascalientes, México. 1rojas@edu.cumbresaguascalientes.com 
un centro escolar privado del municipio de Aguascalientes, a quienes se les aplicó un instrumento diseñado para medir la variable de estudio. El análisis de resultados permite validar el instrumento diseñado, al identificar niveles buenos de consistencia interna y validez de constructo. Se revela un avance estadísticamente significativo en el grado de autorregulación de los aprendizajes en los alumnos entre los periodos de aplicación de la escala, identificando a su vez un grado significativamente mayor de autorregulación en estudiantes mujeres que en varones. Estos resultados son relevantes, ya que además de colaborar con la sustentación científica del enfoque educativo oficial del país -centrado en el desarrollo de competencias-, contribuyen con un instrumento contextualizado para México y brindan luz respecto de la modalidad online que, de modo irremediable, se seguirá aplicando mientras que la pandemia de la COVID-19 lo demande.

Palabras clave: enfoque por competencias, autorregulación del aprendizaje, educación online, educación secundaria, educación media superior, COVID-19, México.

\section{ABSTRACT}

Given the official declaration of COVID-19 as a pandemic by the World Health Organization, Mexico declared in March 2020 the suspension of face-to-face activities in educational centers through an Agreement promulgated in the Official Journal of the Federation. This suspension lasted until the end of the school year, causing students, teachers and managers to implement a distance modality to continue the training process. The present study pursues the objective of determining if the degree of self-regulation of the learning of students of Middle and High school education suffered any significant change due to this new modality. For this, a non-experimental and longitudinal study was developed, with an exploratory and descriptive scope. A sample of 206 students from a private school in the municipality of Aguascalientes was considered, to whom an instrument designed to measure the study variable was applied. The analysis of results allows validating the designed instrument, by identifying good levels of internal consistency and construct validity. A statistically significant advance in the degree of self-regulation of learning in students was revealed between the periods of application of the scale, identifying a significantly higher degree of self-regulation in female students than in males. These results are relevant, since in addition to collaborating with the scientific support of the country's official educational approach, focused on the development of competencies, contributes with an instrument for Mexico and the shed of light related to the online modality that will inevitably continue to be applied until the COVID-19 as long as the pandemic demands it.

Key words: Competence Paradigm, Self-regulation of Learning, Online Learning, Middle Education, High School Education, COVID-19, Mexico.

\section{INTRODUCCIÓN}

Como efecto de la globalización y los avances tecnológicos, los enfoques educativos de los distintos países han evolucionado en las últimas décadas con la firme intención de adaptarse a los nuevos contextos y responder a las necesidades educativas inherentes a los mismos. En el caso de México, la doctora Laura Frade (Pacheco-Rocha, 2014) establece que de un enfoque centrado en el profesor, con un fundamento conductista y enfatizado en la trasmisión de saberes y la repetición de los mismos por 
el alumnado (1973), se migró a un enfoque constructivista (1993), en el que se colocaba en el centro al estudiante y se concebía al profesor como un guía capaz de diseñar experiencias de aprendizaje para llevar al propio alumno a construir nuevos saberes sobre sus esquemas previos, y evolucionar sus estructuras mentales (teoría psicocognitiva de Piaget), a través de la interacción y andamiaje con los pares y profesores (teoría del aprendizaje sociocultural de Vygotsky), en aras de llevar a la vida diaria los nuevos saberes configurados (teoría del aprendizaje significativo de Ausubel).

Más adelante, en 2006, surgió el enfoque centrado en el desarrollo de competencias como efecto de las demandas del sector empresarial, cuyos empleadores afirmaban que los egresados de educación superior poseían múltiples conocimientos teóricos sobre la profesión, pero reflejaban en sus prácticas un insuficiente grado de desarrollo de competencias para enfrentar las funciones esperadas. Aunque mantenía fundamentos constructivistas, este enfoque vislumbraba como finalidad educativa prioritaria el logro de desempeños pertinentes en contextos diferenciados, a través de la armónica conjunción de conocimientos, habilidades y actitudes, así como la transversalidad e interdisciplinariedad entre áreas de conocimientos, y la incorporación de metodologías activas como métodos para el aprendizaje (Pimienta, 2012).

Dentro de este nuevo enfoque centrado en competencias, la acumulación de conocimientos deja de tener la misma relevancia que antes, siendo sustituida por aspectos como el aprender a buscar y seleccionar ideas correctas, distinguir información errónea u obsoleta (Esteve, 2003), así como desarrollar la habilidad para gestionar los propios aprendizajes (UNESCO, 1998). Será en el último aspecto en el que se centrará la atención en este estudio, ante la relevancia que ha tenido la autorregulación del aprendizaje frente al enfoque por competencias.

La autorregulación del aprendizaje ha cobrado cada vez más preeminencia debido a los cambios socio-tecnológicos y a la aceleración de los procesos de producción del conocimiento, enmarcados en el contexto del siglo XXI. Este constructo puede entenderse como un conjunto de pensamientos, emociones y acciones que los estudiantes despliegan en función de sus objetivos de aprendizaje. En este sentido, los aprendices autorregulados son metacognitivamente, emocionalmente y comportamentalmente activos (Duchovicova y Dominika, 2019; Yarnall, Freed y Malone, 2019).

Las características anteriores son necesarias en los estudiantes actuales, por lo que los centros educativos han debido realizar una migración en los paradigmas y las estrategias de enseñanza para promover y construir escenarios de aprendizaje que promuevan la autorregulación. Por consiguiente, el paradigma actual, centrado en competencias, ha sido conformado por diversos autores. En el presente trabajo asumimos la postura socio-constructivista al concebir a las competencias como un conjunto articulado y orquestado de recursos cognitivos, emocionales, actitudinales y de comportamiento que se despliegan, situados en la práctica dentro de contextos diferenciados en los que existe interacción social (Masciotra, Jonnaert y Daviau, 2004; Masciotra, Roth y Morel, 2007; Perrenoud, 2008, 2009). En este sentido, desde el enfoque por competencias cobra relevancia -más que la repetición de conocimientos- la movilización de saberes que permitan incorporar las características de los estudiantes y su zona de aprendizaje próximo.

En la revisión de literatura sobre el concepto de autorregulación, ubicamos múltiples enfoques y teóricos que lo han abordado. Primeramente, la propuesta de Bandura (1977) introduce en su «Teoría del Aprendizaje Social», el concepto de autorregulación y autoeficacia. Posteriormente, los trabajos de Zimmerman (1995; 1998; 2011) 
relacionan la autorregulación con el aprendizaje, definiendo la variable «autorregulación del aprendizaje» como el grado en el que cada alumno tiene un papel activo y creativo en su proceso de aprendizaje, abarcando este la cognición, metacognición, motivación y conducta (Peñalosa, Landa y Vega, 2006).

Por lo tanto, distintos autores (ver tabla 1) han centrado sus acciones investigativas en esta variable a fin de comprenderla, definirla, medirla y explicar posibles causas y efectos asociadas con ella. En cuanto a su configuración, la revisión de literatura permitió identificar coincidencia relacionada a tres dimensiones o constructos torales que la configuran. En la tabla 1 se presenta una síntesis al respecto. Podrá observarse que dichas dimensiones son relativas a: 1) aspectos motivacionales que envuelven el proceso de aprendizaje; 2) selección y aplicación autónoma y guiada de estrategias cognitivas, antes y durante el proceso de aprendizaje, y 3) implementación de acciones de autoevaluación y regulación metacognitiva antes, durante y después de la experiencia de aprendizaje.

Tabla 1. Dimensiones constitutivas de la autorregulación del aprendizaje

\section{DIMENSIONES SUBDIMENSIONES}

Aspectos motivacionales. $\checkmark$ Creencias motivacionales: autoeficacia, valor intrínseco y ansiedad (Pintrich y De Groot, 1990).

$\checkmark$ Orientaciones de objetivos personales y sus percepciones por parte de los profesores y los padres, así como creencias, actitudes y estrategias relacionadas con el logro (Midgley et al., 2000).

$\checkmark$ Involucramiento personal frente al desarrollo de una tarea específica (López, Hederich-Martínez y Camargo, 2001).

$\checkmark$ Formulación propia de metas de aprendizaje (Muchiut et al., 2008).

$\checkmark$ Estructuración del ambiente y establecimiento de metas en ambientes de aprendizaje por Internet (Barnard, Lan, To, Paton y Lai, 2008).

$\checkmark$ Autoeficacia para aplicación de estrategias, metas de aprendizaje, logro y utilidad asumida para la autorregulación (Fernández et al., 2013).

$\checkmark$ Gestión de la motivación y del contexto (Núñez, Amieiro, Álvarez, García y Dobarro, 2015).

$\checkmark$ Control individual del ambiente (Kaplan, Montalembert, Laurent y Fenouillet, 2017).

$\checkmark$ Potenciación de la motivación y confianza; trabajar la autoestima y la capacidad de aceptar el rechazo que provoca el error, así como potenciar la experimentación del placer generado ante el logro del aprendizaje (Universidad Internacional de Valencia, 2018). 
DIMENSIONES

Habilidades cognitivas.

\section{SUBDIMENSIONES}

$\checkmark$ Planeación, estrategias de manejo de información y monitoreo (Schraw y Denisson, 1994; Balcikanli, 2011).

$\checkmark$ Uso de estrategias de aprendizaje autorregulado (Pintrich y De Groot, 1990).

$\checkmark$ Búsqueda de información y aprendizaje (Cleary, 2006).

$\checkmark$ Elección e implementación de estrategias de aprendizaje adecuadas (Muchiut et al., 2008).

$\checkmark$ Gestión del tiempo, búsqueda de ayuda y estrategias para el desarrollo de tareas en ambientes de aprendizaje por Internet (Barnard et al., 2008).

$\checkmark$ Aprovechamiento del tiempo de estudio (Fernández et al., 2013).

$\checkmark$ Gestión de la planificación y de la cognición (Núñez et al., 2015).

$\checkmark$ Anticipación individual de materiales y referencias, y decisiones colectivas para los cambios en el método (Kaplan et al., 2017).

$\checkmark$ Potenciar las capacidades metalingüísticas y la adopción de distintos roles, así como aplicar medios para superar obstáculos para obtener, procesar y asimilar nuevos conocimientos (Universidad Internacional de Valencia, 2018).

Autoevaluación y metacognición.

$\checkmark$ Estrategias de depuración y evaluación del aprendizaje (Schraw y Dennison, 1994).

Aplicación de proceso de autoevaluación de los resultados de aprendizaje (Muchiut et al., 2008).

$\checkmark$ Autoevaluación en ambientes de aprendizaje por Internet (Barnard et al., 2008).

$\checkmark$ Monitoreo y evaluación (Balcikanli, 2011; Jaramillo y Osses, 2012).

$\checkmark$ Elaboración de diagnóstico sobre necesidades particulares y de aprendizaje, y comprensión del propio aprendizaje y de los procesos del pensamiento (Vives-Varela, Durán-Cárdenas, Varela-Ruíz y Fortoul, 2013).

$\checkmark$ Evaluación de la comprensión (Núñez et al., 2015).

$\checkmark$ Seguimiento y monitoreo individual, evaluación colectiva del contenido y evaluación individual del método (Kaplan et al., 2017).

$\checkmark$ Tomar conciencia sobre las necesidades y procesos de aprendizaje, y adquirir competencias metacognitivas que regulen los propios procesos (Universidad Internacional de Valencia, 2018).

Dada la relevancia pedagógica de la autorregulación del aprendizaje, el recorrido histórico de la investigación hecha al respecto identifica distintas propuestas de instrumentos encaminados a su medición. A continuación, se enlistan algunos con sus respectivos autores y las dimensiones consideradas en su diseño. 
$\checkmark$ Motivational Strategies for Learning Questionnaire (MSLQ) (Pintrich y De Groot, 1990). Los reactivos miden dos constructos: a) creencias motivacionales (autoeficacia, valor intrínseco y ansiedad), y b) estrategias de aprendizaje autorregulado.

$\checkmark$ Metacognitive Awareness Inventory (MAI) (Shraw y Dennison, 1994). Contempla reactivos para ocho dimensiones: a) conocimiento declarativo; b) conocimiento procedimental; c) aprendizaje condicional; d) planeación; e) estrategias para el manejo de la información; f) monitoreo; g) estrategias de depuración, y h) evaluación del aprendizaje.

$\checkmark$ Patterns of Adaptative Learning Scales (PALS) (Midgley et al., 2000). Cuenta con subescalas que miden aspectos relativos a estudiantes y profesores. Para los primeros, contempla: a) orientaciones de los objetivos personales; b) percepción de los objetivos de los profesores; c) percepciones de estructuras y objetivos del aula; d) creencias, actitudes y estrategias relacionadas con el logro, y e) percepciones sobre los padres, la vida en el hogar y la cultura.

Para los docentes: a) percepción sobre estructura de los objetivos de la escuela y sobre el desarrollo de los alumnos; b) percepciones sobre la relación de los enfoques educativos y los objetivos, y c) percepción relativa a la eficacia de la enseñanza personal.

$\checkmark$ Self-regulation Strategy Inventory-Self Report (SRSI-SR) (Barnard et al., 2008). Orientado al aprendizaje en ambientes online, contempla seis dimensiones: a) estructuración del ambiente; b) establecimiento de metas; c) gestión del tiempo; d) búsqueda de ayuda; e) estrategias para el desarrollo de tareas, y f) autoevaluación.

$\checkmark$ Metacognitive Awareness Inventory for Teachers (MAIT) (Balcikanli, 2011). Involucra seis dimensiones: a) conocimiento declarativo; b) conocimiento procedimental; c) conocimiento condicional; d) planeación; e) monitoreo, y f) evaluación.

$\checkmark$ Escala de Evaluación de la Autorregulación a partir de Textos (ARATEX-R) (Núñez et al., 2015). Contempla cinco aspectos: a) gestión de la planificación; b) gestión de la cognición; c) gestión de la motivación; d) evaluación de la comprensión, y e) gestión del contexto.

$\checkmark$ Escala de Regulación Individual y Colectiva del Aprendizaje (ERICA) (Kaplan, Montalembert, Laurent y Fenouillet, 2017). Se constituye por seis ámbitos: a) anticipación individual de materiales y referencias; $b$ ) control individual del ambiente; $c$ ) seguimiento y monitoreo individual; d) evaluación colectiva del contenido; e) evaluación individual del método, y f) decisiones colectivas para los cambios en el método.

Resulta interesante señalar que, en la literatura, no se reconocen instrumentos validados que midan la variable autorregulación del aprendizaje en el contexto mexicano, aspecto que se considera necesario ante el reto de dotar de cientificidad al enfoque centrado en competencias que sea opera en el país, desde 2006. Asimismo, se identifica que varias propuestas, si bien son propositivas y suman beneficios a nivel investigativo y pedagógico, no necesariamente contemplan aspectos de innovación educativa relativamente recientes, como las denominadas «metodologías activas», entre las que encontramos algunas alternativas como el aprendizaje basado en problemas, los proyectos, los estudios de caso, las simulaciones, el aula invertida, entre otras. En este sentido, el presente estudio cobra relevancia al implicar el diseño y la aplicación de un instrumento de medición contextualizado para México, ante las tendencias de innovación educativa. 
Otro motivo que dota de suma relevancia este estudio es que considera un factor ajeno al ámbito pedagógico que en el presente incide con énfasis sobre el hecho educativo. El ciclo escolar 2019-20 ha sido indiscutiblemente atípico en la mayoría de los países -incluido México-, ya que una pandemia sanitaria ha afectado los distintos sectores sociales y económicos, provocando dentro del ámbito educativo el cierre de las instituciones educativas de los distintos niveles en nuestro país, desde marzo de 2020.

De acuerdo con Naciones Unidas México (2020), la COVID-19 es una enfermedad infecciosa provocada por el coronavirus que se ha descubierto más recientemente: SARS-CoV-2. El primer brote se originó en Wuhan, China, en diciembre de 2019, extendiéndose a lo largo de los continentes durante los primeros meses de 2020. Los síntomas más comunes son fiebre, tos seca y cansancio, aunque también se presentan en algunos casos dolores, congestión nasal, rinorrea, dolor de garganta o diarrea. Se declara que la mayoría de las personas -aproximadamente $80 \%$ - se recuperan sin necesidad de algún tratamiento oficial, y alrededor del $17 \%$ presentan graves problemas además de dificultad para respirar. Las personas mayores, así como quienes padecen afecciones médicas como hipertensión arterial, problemas cardiacos o diabetes, tienen mayores probabilidades de caer en enfermedad grave. Además, en torno al $2 \%$ de las personas que contraen la enfermedad, mueren.

Las investigaciones del sector médico revelan que el virus causante de la COVID-19 se trasmite primordialmente por contacto con gotículas procedentes de la nariz o la boca de personas contagiadas que tosen, exhalan o estornudan. Estas pueden caer sobre objetos o superficies que, de ser tocadas por personas sanas, pueden provocar el contagio ante el contacto de las propias manos con ojos, nariz o boca (Naciones Unidas México, 2020).

Ante los alarmantes niveles de propagación de la enfermedad y debido a su gravedad, la Organización Mundial de la Salud (OMS) (2020) determinó, el 11 de marzo de 2020, que la COVID-19 podía caracterizarse como una pandemia. Lo anterior provocó que en México, el 16 de marzo de 2020, se promulgara el Acuerdo 16/03/2020 en el Diario Oficial de la Federación, en el que se estipulaba que se suspendían las clases de educación preescolar, primaria, secundaria, normal y demás, para la formación de maestros de educación básica del Sistema Educativo Nacional, así como aquellas de los tipos medio superior y superior dependientes de la Secretaría de Educación Pública (Secretaría de Gobernación, 2020). Lo anterior se decidió ante los niveles alarmantes de propagación y gravedad y a fin de salvaguardar la seguridad de los habitantes y visitantes de México. El tiempo de vigencia de dicha suspensión abarcó del 23 de marzo al 17 de abril de 2020, temporalidad que fue extendida de modo gradual hasta la finalización del ciclo escolar y durante la cual, las escuelas, universidades y demás instituciones educativas implementaron mecanismos diversos para migrar de una modalidad educativa presencial a una modalidad a distancia, valiéndose de recursos tecnológicos como Internet y el uso de plataformas virtuales, la programación de programas educativos en canales de televisión de libre señal, entre otros. A su vez, dejando rezagados a niños y jóvenes de contextos menos favorecidos que por la falta de acceso a estos recursos y de cobertura de servicios de Internet o señal de televisión, no pudieron dar continuidad a sus estudios.

Ante este escenario, un amplio campo de investigación educativa se vislumbra respecto de los aspectos, efectos y las consideraciones que el cambio de modalidad educativa provocó en los estudiantes de los distintos niveles educativos, respecto de su aprendizaje y desarrollo integral. En un afán de contribuir con ello, el presente estudio persigue el objetivo de determinar si el grado de autorregulación del aprendizaje de los estudiantes de educación secundaria y media superior sufrió alguna modificación estadísticamente 
significativa ante el cambio de modalidad presencial a modalidad online, ante el confinamiento y el cierre de planteles provocado ante la pandemia sanitaria de la COVID-19.

Para lo anterior, se realizó un estudio en un centro escolar particular del estado de Aguascalientes, en donde se aplica desde 2006 el enfoque centrado en competencias a través de la vivencia de metodologías activas como el ABP, estudio de casos, proyectos, simulaciones, gamificación, entre otras; todas con elementos de trabajo independiente y colaborativo. A raíz de la pandemia, el cambio a una modalidad de educación online provocó ajustes en la aplicación del enfoque, enfatizándose más la metodología de proyectos, el trabajo colaborativo mediante recursos online (Google), así como la elaboración de un portafolios anual de evidencias que privilegió la autoevaluación y metacognición. Este fue presentado por cada estudiante a sus padres, compañeros y profesores, el último día de clases.

Se asume como relevante este tema al permitir medir si hubo o no algún efecto -positivo o negativo- en los estudiantes participantes, así como por el hecho de que no hay una clara perspectiva respecto de la duración del confinamiento a nivel federal y estatal, pudiendo continuar la clausura de los planteles educativos de modo indefinido durante el ciclo escolar subsecuente (2020-21).

Aunado a esto, el presente estudio brinda, como contribución adicional, la validación de un instrumento para medir la variable autorregulación del aprendizaje en el contexto educativo mexicano, cuyo diseño es congruente con el enfoque educativo contemporáneo, centrado en el desarrollo de competencias. Este contempló las tres dimensiones torales que fueron identificadas en la revisión de la literatura: a) motivación y actitud hacia el aprendizaje; b) estrategias cognitivas, y c) autoevaluación y regulación metacognitiva. Los reactivos fueron adecuados al enfoque por competencias aplicado en el centro escolar, considerando los aspectos antes mencionados que se enfatizaron a raíz del cambio de modalidad.

\section{MÉTODO}

Esta sección presenta el diseño metodológico que se consideró para la realización del estudio.

\subsection{Diseño}

Se desarrolló un estudio cuantitativo con diseño no experimental, de tipo longitudinal, y con alcance exploratorio y descriptivo (Hernández, Fernández y Baptista, 2014). Fue no experimental debido a que no hubo un tratamiento, sino únicamente una medición de la variable de estudio (autorregulación del aprendizaje). Se trató de una investigación longitudinal al contemplar dos mediciones en distintos momentos (al inicio y al final del ciclo escolar). El alcance fue exploratorio y descriptivo, ya que no se identificaron investigaciones previas con este planteamiento y la intención del análisis de datos se limitó a una primera descripción de la diferencia observada en la variable de estudio entre las dos mediciones realizadas, en aras de dar continuidad en futuros estudios.

En este se hicieron dos mediciones de la variable autorregulación del aprendizaje durante los meses de septiembre de 2019 y junio de 2020, respectivamente. Resulta importante destacar que la primera medición se realizó con fines distintos al planteamiento de este estudio, ya 
que la contingencia de salud ocurrió hasta el mes de marzo de 2020, siendo de interés capitalizar los datos para la realización de esta investigación.

\subsection{Delimitación de la muestra}

La recolección de datos se realizó considerando la población estudiantil de secundaria y bachillerato de un colegio privado del municipio de Aguascalientes, que atiende a familias de nivel socioeconómico medio alto y alto. El muestreo se realizó a juicio de los investigadores, descartando a los alumnos de $7^{\circ}$ grado ( $1^{\circ}$ de secundaria), al considerar que su ingreso al nivel secundaria era reciente, aspecto que podría sesgar la medición ante la inexperiencia académica de los estudiantes y el factor motivacional propio del ingreso reciente a dicho nivel.

En este sentido, la población escolar (secundaria y bachillerato) estaba constituida por 309 estudiantes, de los cuales se descartaron 103, quedando como casos válidos para el estudio 206. El descarte obedeció al criterio de restricción (cursar primer grado de secundaria), así como a casos en los que los alumnos por alguna razón no contestaron el instrumento en alguna de las dos aplicaciones programadas, aspecto que impedía valorar su respectivo avance o retroceso en la variable de estudio. En la siguiente tabla se presenta la distribución de la muestra por grado y sexo:

Tabla 2. Muestra

\begin{tabular}{|c|c|c|c|}
\hline GRADO ESCOLAR & MUJERES & VARONES & TOTAL \\
\hline $2^{\circ}$ de secundaria. & 17 & 17 & 34 \\
\hline $3^{\circ}$ de secundaria. & 22 & 23 & 45 \\
\hline $1^{\circ}$ de bachillerato. & 31 & 28 & 59 \\
\hline $2^{\circ}$ de bachillerato. & 18 & 14 & 32 \\
\hline $3^{\circ}$ de bachillerato. & 21 & 15 & 36 \\
\hline Total & 109 & 97 & 206 \\
\hline
\end{tabular}

\subsection{Diseño del instrumento y validez de contenido}

La recolección de datos se realizó a través de un instrumento diseñado para este fin, denominado Escala de Autorregulación del Aprendizaje (ESAA), mismo que se presenta en el anexo A. La escala se componía por 40 reactivos clasificados en tres dimensiones o constructos constitutivos identificados en la literatura. Estos fueron: a) D1. Motivación y actitud hacia el aprendizaje (10 reactivos); b) D2. Estrategias cognitivas (16 reactivos); c) D3. Autoevaluación y regulación metacognitiva (14 reactivos). En la tabla 3 se presenta la operacionalización de variables que orientó el diseño del instrumento en atención de sus respectivas dimensiones e indicadores. 
Tabla 3. Operacionalización de la variable autorregulación del aprendizaje

\begin{tabular}{|c|c|c|c|}
\hline VARIABLE & DIMENSIONES & INDICADORES & REACTIVOS \\
\hline \multirow{10}{*}{$\begin{array}{l}\text { Autorregulación } \\
\text { en el } \\
\text { aprendizaje. }\end{array}$} & \multirow{3}{*}{$\begin{array}{c}\text { D1: } \\
\text { Motivación y } \\
\text { actitud hacia el } \\
\text { aprendizaje. }\end{array}$} & $\begin{array}{l}\text { Sentido de autoeficacia ante las } \\
\text { demandas de la tarea de aprendizaje. }\end{array}$ & $7,8,9,10$ \\
\hline & & $\begin{array}{l}\text { Motivación intrínseca por la tarea: } \\
\text { apreciación de utilidad, relevancia } \\
\text { personal e impacto social. }\end{array}$ & $1,2,3$ \\
\hline & & $\begin{array}{l}\text { Orientación al buen rendimiento } \\
\text { académico. }\end{array}$ & $4,5,6$ \\
\hline & \multirow{4}{*}{$\begin{array}{l}\text { D2: } \\
\text { Estrategias } \\
\text { cognitivas. }\end{array}$} & $\begin{array}{l}\text { Planificación pertinente y ejecución } \\
\text { segura y estratégica de acciones de } \\
\text { aprendizaje. }\end{array}$ & $\begin{array}{l}13,14,15,16,18 \\
19,22,2326 .\end{array}$ \\
\hline & & $\begin{array}{l}\text { Uso pertinente de materiales físicos } \\
\text { y/o electrónicos para resolver la } \\
\text { tarea. }\end{array}$ & 24,25 . \\
\hline & & $\begin{array}{l}\text { Andamiaje y trabajo colaborativo con } \\
\text { los pares. }\end{array}$ & $17,20,21$ \\
\hline & & $\begin{array}{l}\text { Identificación de conocimientos y } \\
\text { experiencias previas relacionadas } \\
\text { con la tarea de aprendizaje. }\end{array}$ & $11,12$. \\
\hline & \multirow{3}{*}{$\begin{array}{c}\text { D3: } \\
\text { Autoevaluación } \\
\text { y regulación } \\
\text { metacognitiva. }\end{array}$} & $\begin{array}{l}\text { Autoevaluación, metacognición } \\
\text { e identificación y superación de } \\
\text { obstáculos de aprendizaje. }\end{array}$ & $\begin{array}{l}27,28,31,32,33 \\
34,35,36,39,40 .\end{array}$ \\
\hline & & $\begin{array}{l}\text { Capacidad de mantener la atención } \\
\text { en la tarea. }\end{array}$ & $37,38$. \\
\hline & & Autocontrol ante el estrés académico. & 29,30 . \\
\hline
\end{tabular}

Los ítems se redactaron en forma de escala tipo Likert de cinco niveles, donde el estudiante plasmaba su grado de acuerdo con la presencia de cada aspecto contemplado en la afirmación. A estos antecedían algunos reactivos de identificación como el grado, el sexo y los años de antigüedad en el plantel educativo.

Previa aplicación del instrumento se realizó un análisis de la validez de contenido a través del método de jueceo de expertos. Para ello se solicitó a dos expertos evaluar la congruencia ítem-indicador, la suficiencia de reactivos para la medición de la variable de estudio, así como la claridad y pertinencia de su redacción. Las valoraciones respecto de congruencia ítem-indicador y suficiencia de ítems fueron positivas. La única retroalimentación que se brindó fue relativa a leves aspectos de redacción en tres reactivos, aspectos que fueron atendidos al considerarse procedentes. 


\subsection{Análisis psicométrico del instrumento}

La calidad psicométrica del instrumento se evaluó mediante la revisión de dos atributos: a) consistencia interna, y b) validez de constructo.

\subsubsection{Consistencia interna del instrumento}

La consistencia interna de la ESAA se valoró mediante el coeficiente Alpha de Cronbach, mismo que se calculó para cada dimensión constitutiva (subescala) del instrumento. En la tabla 4 se presentan los resultados.

Tabla 4. Consistencia interna del instrumento

\begin{tabular}{|c|c|c|c|}
\hline Subescala & $\begin{array}{c}\text { D1. Motivación y actitud } \\
\text { hacia el aprendizaje }\end{array}$ & $\begin{array}{c}\text { D2. Estrategias } \\
\text { cognitivas }\end{array}$ & $\begin{array}{c}\text { D3. Autoevaluación } \\
\text { y regulación } \\
\text { metacognitiva }\end{array}$ \\
\hline Alpha & .838 & .853 & .861 \\
\hline Valoración & Buena & Buena & Buena \\
\hline
\end{tabular}

Se puede apreciar que los valores del Alpha de Cronbach para cada una de las secciones de la ESSA son buenos, al estar por encima de 0.7 (Nunnally y Bernstein, 1994). Por tanto, el instrumento cuenta con buena consistencia interna.

\subsubsection{Validez de constructo del instrumento}

Para este análisis se utilizó la base de datos de la segunda aplicación, al haber sido en la que se logró mayor cantidad de instrumentos con respuesta registrada en todos los reactivos (258 casos).

La validez de contenido se revisó a través de dos métodos. El primero consistió en un análisis ítem-dominio, a fin de identificar si se observaba correlación estadísticamente significativa entre los reactivos y su respectivo puntaje medio de dimensión (D1, D2 y D3). Para ello, se utilizó el coeficiente de correlación no paramétrico Rho de Spearman, al tener los ítems una escala de medición ordinal y el puntaje de las dimensiones una naturaleza cuantitativa. En la tabla 5 se presentan los resultados obtenidos. 
Tabla 5. Correlación ítem-dominio de las subescalas de la ESAA

\section{D1. Motivación y actitud hacia el aprendizaje}

\begin{tabular}{|c|c|c|c|c|c|c|c|c|c|c|}
\hline & $\mathrm{R} 1$ & $\mathrm{R} 2$ & $\mathrm{R} 3$ & $\mathrm{R} 4$ & $\mathrm{R} 5$ & $\mathrm{R} 6$ & $\mathrm{R} 7$ & $\mathrm{R} 8$ & $\mathrm{R} 9$ & $\mathrm{R} 10$ \\
\hline Rho & .65 & .62 & .52 & .65 & .51 & .68 & .62 & .58 & .57 & .61 \\
\hline Sig. & .000 & .000 & .000 & .000 & .000 & .000 & .000 & .000 & .000 & .000 \\
\hline
\end{tabular}

D2. Estrategias cognitivas

\begin{tabular}{|l|c|c|c|c|c|c|c|c|c|c|c|c|c|c|c|c|}
\hline & $\mathrm{R} 11$ & $\mathrm{R} 12$ & $\mathrm{R} 13$ & $\mathrm{R} 14$ & $\mathrm{R} 15$ & $\mathrm{R} 16$ & $\mathrm{R} 17$ & $\mathrm{R} 18$ & $\mathrm{R} 19$ & $\mathrm{R} 20$ & $\mathrm{R} 21$ & $\mathrm{R} 22$ & $\mathrm{R} 23$ & $\mathrm{R} 24$ & $\mathrm{R} 25$ & $\mathrm{R} 26$ \\
\hline Rho & .52 & .42 & .62 & .63 & .63 & .52 & .58 & .51 & .57 & .47 & .48 & .57 & .61 & .39 & .39 & .53 \\
\hline Sig. & .000 & .000 & .000 & .000 & .000 & .000 & .000 & .000 & .000 & .000 & .000 & .000 & .000 & .000 & .000 & .000 \\
\hline
\end{tabular}

D3. Autoevaluación y regulación metacognitiva

\begin{tabular}{|l|c|c|c|c|c|c|c|c|c|c|c|c|c|c|c|}
\hline & $\mathrm{R} 26$ & $\mathrm{R} 27$ & $\mathrm{R} 28$ & $\mathrm{R} 29$ & $\mathrm{R} 30$ & $\mathrm{R} 31$ & $\mathrm{R} 32$ & $\mathrm{R} 33$ & $\mathrm{R} 34$ & $\mathrm{R} 35$ & $\mathrm{R} 36$ & $\mathrm{R} 37$ & $\mathrm{R} 38$ & $\mathrm{R} 39$ & $\mathrm{R} 40$ \\
\hline Rho & .54 & .60 & .53 & .59 & .66 & .66 & .53 & .64 & .61 & .65 & .49 & .55 & .62 & .58 & .54 \\
\hline Sig. & .000 & .000 & .000 & .000 & .000 & .000 & .000 & .000 & .000 & .000 & .000 & .000 & .000 & .000 & .000 \\
\hline
\end{tabular}

En todos los casos se identificaron correlaciones estadísticamente significativas $($ Sig. $=.000)$. La fuerza de correlación se interpretó tomando como referencia la propuesta de Dancey y Reidy, quienes la analizan desde el campo psicológico y establecen que de 0.01 a 0.39 es baja, de 0.4 a 0.69 es moderada, y de 0.7 a 0.99 es fuerte (Akoglu, 2018). En este sentido se identifica que solo dos reactivos observaron una fuerza baja (R24 y R25).

Se prosiguió este análisis generando una tabla con la correlación de Pearson entre las subescalas (D1, D2 y D3) y el puntaje de autorregulación (GAA), mismo que se calculó en la base de datos a través del promedio de las tres dimensiones constitutivas. En la tabla 6 se presentan los resultados. 
Tabla 6. Correlación de Pearson entre D1, D2, D3 y GAA

\begin{tabular}{|c|c|c|c|c|}
\hline & $\begin{array}{l}\text { D1. } \\
\text { Motivación y actitud } \\
\text { hacia el aprendizaje }\end{array}$ & $\begin{array}{l}\text { D2. } \\
\text { Estrategias } \\
\text { cognitivas }\end{array}$ & $\begin{array}{c}\text { D3. } \\
\text { Autoevaluación } \\
\text { y regulación } \\
\text { metacognitiva }\end{array}$ & $\begin{array}{c}\text { GAA. } \\
\text { Grado de } \\
\text { autorregulación del } \\
\text { aprendizaje }\end{array}$ \\
\hline D1 & $r=1$ & & & \\
\hline D2 & $\begin{array}{c}r=.793 \\
\text { Sig. }=.000\end{array}$ & $r=1$ & & \\
\hline D3 & $\begin{array}{c}r=.669 \\
\text { Sig. }=.000\end{array}$ & $\begin{array}{c}r=.766 \\
\text { Sig. }=.000\end{array}$ & $r=1$ & \\
\hline GAA & $\begin{array}{c}r=.900 \\
\text { Sig. }=.000\end{array}$ & $\begin{array}{c}r=.930 \\
\text { Sig. }=.000\end{array}$ & $\begin{array}{c}r=.900 \\
\text { Sig. }=.000\end{array}$ & $r=1$ \\
\hline
\end{tabular}

Se aprecia que todas las correlaciones son estadísticamente significativas (Sig. $=.000)$ con puntajes que representan alta fuerza de correlación entre subescalas y puntaje global (valores mayores a 0.7). Centrando la atención en los puntajes de D1, D2 y D3 con respecto de GAA, podemos encontrar valores muy altos, mismos que al ser elevados al cuadrado proporcionan el coeficiente de determinación, valor que indica la proporción de la variable GAA que se puede explicar en función de los constructos constitutivos $\left(\mathrm{r}_{(\mathrm{D} 1)}^{2}=81.0 \%, \mathrm{r}_{(\mathrm{D} 2)}^{2}=86.49 \%, \mathrm{r}_{(\mathrm{D} 3)}^{2}=81 \%\right)$.

Dado el análisis anterior, surge evidencia suficiente para concluir que el instrumento cuenta con adecuada validez de constructo, al observar correlación significativa entre los ítems y los puntajes de sus respectivos dominios, así como fuertes correlaciones entre dimensiones y puntaje global de la escala. A fin de reafirmar este juicio se aplicó, como segundo mecanismo, un análisis factorial exploratorio para cada subescala. La tabla 7 presenta un resumen de dichos modelos, contemplando el método de extracción y rotación, las comunalidades, las medidas KMO y de Esfericidad de Bartlett, la varianza explicada, la matriz de estructura, las correlaciones entre componentes, así como las sugerencias de mejora para cada subescala emergida a la luz de los análisis.

Tabla 7. Análisis factorial exploratorio

\begin{tabular}{|c|c|c|c|}
\hline SUBESCALA & D1 & D2 & D3 \\
\hline Extracción. & $\begin{array}{c}\text { Componentes } \\
\text { principales (fijada a 3 } \\
\text { factores). }\end{array}$ & $\begin{array}{c}\text { Componentes } \\
\text { principales (fijada a 4 } \\
\text { factores). }\end{array}$ & $\begin{array}{c}\text { Componentes } \\
\text { principales (fijada a 3 } \\
\text { factores). }\end{array}$ \\
\hline Rotación. & Promax & Promax & Promax \\
\hline Medida KM0. & .829 & .862 & .836 \\
\hline Esfericidad Bartlett. & $\mathrm{x}^{2}=859.759$ & $\mathrm{x}^{2}=1241.844$ & $\mathrm{x}^{2}=1390.671$ \\
Sig. $=.000$ & Sig. $=.000$ & Sig. $=.000$ \\
\hline Comunalidades. & De .453 a . .752 & De .353 a .795 & De .401 a .856 \\
\hline
\end{tabular}




\begin{tabular}{|c|c|c|c|}
\hline SUBESCALA & D1 & D2 & D3 \\
\hline Varianza explicada. & $\begin{aligned} \mathrm{F} 1 & =42.085 \\
\mathrm{~F} 2 & =11.487 \\
\mathrm{~F} 3 & =9.918 \\
\text { Total } & =63.49\end{aligned}$ & $\begin{array}{c}\mathrm{F} 1=32.839 \\
\mathrm{~F} 2=10.366 \\
\mathrm{~F} 3=7.147 \\
\mathrm{~F} 4=6.455 \\
\text { Total }=56.806\end{array}$ & $\begin{aligned} \mathrm{F} 1 & =37.250 \\
\mathrm{~F} 2 & =11.212 \\
\mathrm{~F} 3 & =9.749 \\
\text { Total } & =58.211\end{aligned}$ \\
\hline Matriz de estructura. & $\begin{array}{l}\text { Todos los reactivos } \\
\text { salvo R3 se agruparon } \\
\text { de forma congruente } \\
\text { con la tabla de } \\
\text { operacionalización. } \\
\text { Ver tabla 8. }\end{array}$ & $\begin{array}{c}\text { Todos los reactivos se } \\
\text { agruparon de forma } \\
\text { congruente con la tabla } \\
\text { de operacionalización. } \\
\text { Ver tabla } 9 .\end{array}$ & $\begin{array}{c}\text { Todos los reactivos se } \\
\text { agruparon de forma } \\
\text { congruente con la tabla } \\
\text { de operacionalización. } \\
\text { Ver tabla } 10 .\end{array}$ \\
\hline $\begin{array}{l}\text { Correlaciones entre } \\
\text { componentes. }\end{array}$ & $\begin{array}{c}\text { Se aprecia una } \\
\text { tendencia de } \\
\text { independencia entre } \\
\text { los factores, salvo } \\
\text { en los componentes } \\
\text { F1 y F2. Esto puede } \\
\text { deberse a que el } \\
\text { reactivo } 3 \text { ajustaba } \\
\text { mejor en la F2. Ver } \\
\text { tabla } 8 \text {. }\end{array}$ & $\begin{array}{c}\text { Es necesario reforzar } \\
\text { la independencia entre } \\
\text { los factores, ya que en } \\
\text { los pares F1-F2, F1-F3 } \\
\text { y F2-F3 existen pesos } \\
\text { moderados. Ver tabla } 9 .\end{array}$ & $\begin{array}{c}\text { Se aprecia } \\
\text { independencia entre los } \\
\text { factores, al identificar } \\
\text { coeficientes de } \\
\text { correlación débiles. Ver } \\
\text { tabla } 10 .\end{array}$ \\
\hline Sugerencias. & $\begin{array}{l}\text { Valorar si se modifica } \\
\text { o elimina R3. En } \\
\text { caso de cambiar } \\
\text { la redacción, } \\
\text { mantenerlo como ítem } \\
\text { del mismo indicador. }\end{array}$ & $\begin{array}{l}\text { Revisar los reactivos } \\
\text { que presentan altas } \\
\text { cargas factoriales en } \\
\text { más de un factor (F1 y } \\
\text { F2), a fin de determinar } \\
\text { si es conveniente } \\
\text { modificar su redacción } \\
\text { (R14, R15 y R19). }\end{array}$ & $\begin{array}{l}\text { Valorar la posibilidad } \\
\text { de agregar reactivos } \\
\text { a los indicadores } \\
\text { correspondientes a F2 y } \\
\text { F3, a fin de explicar una } \\
\text { mayor proporción de } \\
\text { varianza. }\end{array}$ \\
\hline
\end{tabular}

En los tres casos, la medida KMO evidencia que existe un buen ajuste, pudiéndose utilizar los datos para un análisis factorial. Por su parte, la Prueba de Esfericidad de Bartlett brinda evidencia suficiente para rechazar la hipótesis nula de esfericidad, asumiendo que los modelos de análisis factorial son adecuados para explicar los datos. Por tanto, es válido aplicar análisis factorial para las tres subescalas.

Para el análisis de los modelos procesados se ha considerado que los pesos factoriales inferiores a 0.3 y los valores comunalidad inferiores a 0.1 son asumidos como no significativos, tal y como establecen los criterios de Raykov y Marcoulides, y Walts et al. (Barrera, 2015). Desde esta perspectiva, observamos que los 40 reactivos reflejaron comunalidades mayores a 0.1 y 39 de ellos (todos, excepto R3) se agruparon con su respectivo componentes-dimensión con cargas factoriales mayores a 0.3, tal y como puede apreciarse en las tablas 8, 9 y 10. 
Tabla 8. Matriz de estructura y correlaciones de D1

\begin{tabular}{|c|c|c|c|}
\hline \multirow{2}{*}{ Reactivos } & \multicolumn{3}{|c|}{ Componentes } \\
\cline { 2 - 4 } & F1 & F2 & F3 \\
\hline R1 & .786 & & \\
\hline R7 & & .435 & \\
\hline R2 & .734 & & \\
\hline R10 & & .473 & \\
\hline R3 & $.237^{*}$ & & \\
\hline R8 & & .726 & \\
\hline R9 & & .655 & \\
\hline R6 & & & .457 \\
\hline R5 & & & .847 \\
\hline R4 & & & .801 \\
\hline
\end{tabular}

Nota: El R3 no ajustó con su componente.

Mapa de calor de las correlaciones entre componentes:

\begin{tabular}{|c|c|c|c|}
\hline Componente & $\mathbf{1}$ & $\mathbf{2}$ & $\mathbf{3}$ \\
\hline 1 & 1.000 & & \\
2 & .503 & 1.000 & \\
3 & .382 & .272 & 1.000 \\
\hline
\end{tabular}

\begin{tabular}{|c|l|}
\hline \multicolumn{2}{|c|}{ Fuerzas de correlación } \\
\hline 1 & Perfecta positiva. \\
\hline 0.7 & Fuerte positiva. \\
\hline 0.4 & Moderada positiva. \\
\hline 0.1 & Baja positiva. \\
\hline 0 & Sin correlación. \\
\hline-0.1 & Baja negativa. \\
\hline-0.4 & Moderada negativa. \\
\hline-0.7 & Fuerte negativa. \\
\hline-1 & Perfecta negativa. \\
\hline
\end{tabular}


Tabla 9. Matriz de estructura y correlaciones de D2

\begin{tabular}{|c|c|c|c|c|}
\hline \multirow{2}{*}{ Reactivos } & \multicolumn{3}{|c|}{ Componentes } & \\
\hline & F1 & F2 & F3 & F4 \\
\hline R22 & .745 & & & \\
\hline R23 & .731 & & & \\
\hline R26 & .661 & & & \\
\hline R13 & .633 & & & \\
\hline R16 & .603 & & & \\
\hline R18 & .585 & & & \\
\hline R24 & & .782 & & \\
\hline R25 & & .721 & & \\
\hline R15 & .584 & & & \\
\hline R14 & .583 & & & \\
\hline R17 & & & .520 & \\
\hline R19 & .545 & & & \\
\hline R20 & & & .889 & \\
\hline R21 & & & .873 & \\
\hline R12 & & & & .823 \\
\hline R11 & & & & .815 \\
\hline
\end{tabular}

Mapa de calor de las correlaciones entre componentes:

\begin{tabular}{|c|c|c|c|c|}
\hline Componente & $\mathbf{1}$ & $\mathbf{2}$ & $\mathbf{3}$ & $\mathbf{4}$ \\
\hline 1 & 1.000 & & & \\
2 & .535 & 1.000 & & \\
3 & .300 & 0.409 & 1.000 & \\
\hline 4 & .409 & .301 & 0.102 & 1.000 \\
\hline
\end{tabular}

\begin{tabular}{|c|l|}
\hline \multicolumn{2}{|c|}{ Fuerzas de correlación } \\
\hline 1 & Perfecta positiva. \\
\hline 0.7 & Fuerte positiva. \\
\hline 0.4 & Moderada positiva. \\
\hline 0.1 & Baja positiva. \\
\hline 0 & Sin correlación. \\
\hline-0.1 & Baja negativa. \\
\hline-0.4 & Moderada negativa. \\
\hline-0.7 & Fuerte negativa. \\
\hline-1 & Perfecta negativa. \\
\hline
\end{tabular}


Tabla 10. Matriz de estructura y correlaciones de D3

\section{Matriz de estructura}

\begin{tabular}{|c|c|c|c|}
\hline \multirow{2}{*}{ Reactivos } & \multicolumn{3}{|c|}{ Componentes } \\
\hline & F1 & F2 & F3 \\
\hline R32 & .745 & & \\
\hline R31 & .741 & & \\
\hline R35 & .726 & & \\
\hline R36 & .722 & & \\
\hline R33 & .653 & & \\
\hline R28 & .642 & & \\
\hline R27 & .638 & & \\
\hline R40 & .631 & & \\
\hline R39 & .602 & & \\
\hline R37 & & .829 & \\
\hline R38 & & .827 & \\
\hline R34 & .554 & & \\
\hline R29 & & & .917 \\
\hline R30 & & & .915 \\
\hline
\end{tabular}

Mapa de calor de las correlaciones entre componentes:

\begin{tabular}{|c|c|c|c|}
\hline Componente & $\mathbf{1}$ & $\mathbf{2}$ & $\mathbf{3}$ \\
\hline 1 & 1.000 & & \\
\hline 2 & .384 & 1.000 & \\
\hline 3 & .316 & .196 & 1.000 \\
\hline
\end{tabular}

\begin{tabular}{|c|l|}
\hline \multicolumn{2}{|c|}{ Fuerzas de correlación } \\
\hline 1 & Perfecta positiva. \\
\hline 0.7 & Fuerte positiva. \\
\hline 0.4 & Moderada positiva. \\
\hline 0.1 & Baja positiva. \\
\hline 0 & Sin correlación. \\
\hline-0.1 & Baja negativa. \\
\hline-0.4 & Moderada negativa. \\
\hline-0.7 & Fuerte negativa. \\
\hline-1 & Perfecta negativa. \\
\hline
\end{tabular}


A la luz de los análisis anteriores se concluye que el instrumento es válido y confiable, por lo que puede fiarse que el análisis de los datos arrojados mediante su recolección es útil para dar respuesta al problema de investigación planteado en este estudio, habiendo precisión y exactitud en la medición de la variable y sus componentes.

En aras de su mejora psicométrica podría revisarse la redacción del R3, a fin de lograr un mejor ajuste con su dimensión (D1. Motivación y actitud hacia el aprendizaje). Asimismo, perfeccionar los reactivos R14, R15 y R19 para evitar que presenten agrupamiento con más de uno de los componentes (indicadores) de su respectiva dimensión (D2. Estrategias cognitivas).

\subsection{Aplicación del instrumento y procesamiento de datos}

La recolección de datos y las demás fases implicadas en el proyecto de investigación se basaron en los principios éticos del Comité de Ética de las Publicaciones (COPE). En este sentido, la investigación se realizó contando con autorización de las autoridades escolares. Asimismo, se explicó a los estudiantes participantes el propósito del instrumento, garantizando la confidencialidad de sus respuestas y asegurando que la participación era voluntaria, sin ningún tipo de consecuencia positiva o negativa por el hecho de hacerlo o abstenerse.

La primera aplicación del instrumento se llevó a cabo en formato físico, bajo el conducto de los profesores titulares de cada grupo, quienes aseguraron una atmósfera ordenada y pertinente para la recolección. Los aplicadores afirmaron que las pocas dudas surgidas por los estudiantes fueron relativas a la forma de llenar la escala, sin haber algún aspecto relevante en cuanto a la comprensión de los reactivos.

La segunda aplicación se llevó a cabo mediante Google Formularios, aplicación vinculada a los correos institucionales del profesorado y los estudiantes. Lo anterior, debido a que la fecha de aplicación coincidió con el periodo de confinamiento por la contingencia sanitaria. En este caso, los profesores titulares guiaron la aplicación vía remota, a fin de asegurar que los alumnos pudieran tener acceso al formulario para su resolución.

Los datos recolectados se procesaron en el software SPSS 26 (IMB), mismo que se utilizó para realizar el análisis estadístico necesario para el análisis psicométrico del instrumento, así como el análisis de los resultados en atención al objetivo de investigación. Este contempló la aplicación de una prueba $\mathrm{T}$ para muestras independientes, para identificar diferencias significativas en los componentes (D1, D2 y D3) y el puntaje global de autorregulación del aprendizaje (GAA) por nivel educativo (Secundaria y Bachillerato) y de modo general. Se aplicó otra prueba T para determinar si había diferencias significativas en función del sexo. A su vez, se categorizó la variable AA en cuatro baremos, para aplicar pruebas chi cuadradas de independencia en contraste con las variables sexo y nivel educativo. Finalmente se calcularon coeficientes de correlación de Pearson para revisar si había relación estadísticamente significativa entre los años de antigüedad en el plantel educativo y los puntajes por dimensión (D1, D2 y D3) y global (GAA).

\subsection{Escenario}

El centro escolar en el que se desarrolló el estudio es un colegio particular del municipio de Aguascalientes que atiende a familias de nivel socioeconómico medio-alto y alto. Se 
localiza en el noreste de la ciudad y ofrece servicios educativos en los niveles de preescolar, primaria, secundaria y media superior. Pertenece a una red de colegios internacional con 65 años de experiencia, presencia en 119 países, y que involucra a 154 colegios y 13 universidades. Es bilingüe y es de los pocos colegios del Estado que ofrece un servicio de educación diferenciada, en la que mujeres y varones toman clases en grupos separados, aunque comparten instalaciones, tiempos de receso y otras actividades que les integran como comunidad. Se promueven los valores católicos, aunque en la matrícula hay estudiantes que practican otras religiones, a quienes se les respetan sus creencias y se les promueve una vida en congruencia con las mismas.

Cotidianamente el servicio se ofrece con modalidad presencial. Los estudiantes asisten a las instalaciones, donde viven distintas experiencias académicas y formativas que contribuyen en el logro del perfil de egreso esperado. En congruencia con la política educativa oficial, el modelo pedagógico aplicado corresponde al enfoque centrado en el desarrollo de competencias, en donde juegan papel relevante las metodologías activas. Cuenta con laboratorios de ciencias, informática, mecatrónica, talleres artísticos, así como un aula Makerspace. En el plano deportivo, tiene varias canchas de futbol, futbol rápido, atletismo y básquetbol.

A raíz del Acuerdo 16/03 / 2020 promulgado en el Diario Oficial de la Federación (Secretaría de Gobernación, 2020), el plantel educativo cerró sus instalaciones, manteniendo activo el servicio educativo con una modalidad online. Lo anterior se operó a través de los servicios de G Suite (Google for Education), mismos que ya eran utilizados por estudiantes y profesores como complemento para la intervención presencial. Las autoridades educativas guiaron a profesores y estudiantes para la programación sincrónica de sesiones, mediante la aplicación Google Meet y se utilizó la plataforma Google Classroom para la trasmisión de materiales de aprendizaje, recursos pedagógicos, así como la entrega y evaluación de productos de aprendizaje. Los exámenes semanales, de periodo y finales se aplicaron a través de la herramienta Google Formularios. Por tanto, no se perdió ningún día de clase de acuerdo con lo establecido por el calendario oficial del Estado.

Si bien los docentes ya estaban familiarizados con estas herramientas tecnológicas, se brindaron, a partir de marzo de 2020 y hasta el resto del ciclo escolar, sesiones de capacitación para perfeccionar el uso, tanto desde una perspectiva técnica, como desde una visión pedagógica. Se impulsó la preparación para enfrentar la certificación Google for Education, aspecto que sigue en proceso. Adicionalmente, las coordinaciones de área brindaron un seguimiento puntual a los docentes, ofreciendo retroalimentación y sugerencias orientadas a la mejora, pero también a la comprensión frente a las dificultades enfrentadas ante el súbito y forzoso cambio de modalidad. Se compartieron también recomendaciones de corte psicológico a fin de mantener una cercanía con cada estudiante, lo más semejante posible a la brindada en la regularidad presencial, así como una atención pertinente a los padres de familia que lo requirieran.

Debido a la complejidad de la pandemia, esta modalidad se extendió todo el ciclo escolar, por lo que las ceremonias de fin de curso se vivieron también a través del uso de las plataformas antes mencionadas. En estas, cada estudiante presentó frente un profesor, varios compañeros y sus propios padres un portafolio de evidencias trabajado durante el ciclo escolar, donde compartía la selección de evidencias que desde su parecer fueron más representativas de cara a los rubros del perfil de egreso institucional. Lo anterior representó un trabajo de autoevaluación y metacognición final que el estudiantado realizaba, siendo el primer ciclo escolar en llevarse a cabo en los colegios de la red. 


\section{RESULTADOS}

El objetivo de investigación consistió en determinar si el grado de autorregulación del aprendizaje en los estudiantes de educación secundaria y media superior sufrió algún cambio significativo (progreso o retroceso) a lo largo de un ciclo escolar, caracterizado por un cambio forzado de modalidad presencial a modalidad online debido a la contingencia sanitaria de la COVID-19. Para dar respuesta al planteamiento se realizó un análisis comparativo entre los puntajes observados en las dos aplicaciones de la ESAA, contemplando cada una de las dimensiones (D1, D2 y D3), así como el grado de autorregulación del aprendizaje (GAA). Para ello se aplicó una Prueba T de muestras relacionadas, contemplando los puntajes por nivel educativo (secundaria y bachillerato), así como el puntaje global (ambos niveles). En la tabla 11 se enlistan los resultados.

Tabla 11. Prueba T para muestras relacionadas

\begin{tabular}{|c|c|c|c|}
\hline Aspecto & Media ${ }^{\circ}$ ESAA & Media ${ }^{\circ}$ ESAA & Significancia \\
\hline D1 Secundaria & 4.11 & 4.30 & .001 \\
\hline D2 Secundaria & 3.92 & 4.15 & .000 \\
\hline D3 Secundaria & 3.58 & 3.81 & .000 \\
\hline GAA Secundaria & 3.87 & 4.08 & .000 \\
\hline D1 Bachillerato & 4.07 & 4.10 & .580 \\
\hline D2 Bachillerato & 3.78 & 3.93 & .003 \\
\hline D3 Bachillerato & 3.36 & 3.61 & .000 \\
\hline GAA Bachillerato & 3.74 & 3.88 & .002 \\
\hline D1 General & 4.09 & 4.18 & .020 \\
\hline D2 General & 3.83 & 4.01 & .000 \\
\hline D3 General & 3.44 & 3.68 & .000 \\
\hline GAA General & 3.79 & 3.96 & .000 \\
\hline
\end{tabular}

Los resultados por nivel educativo evidencian un progreso estadísticamente significativo en todos los aspectos evaluados (valores de significancia inferiores a 0.05). Únicamente en el caso de los estudiantes de bachillerato, el puntaje de la D1 (Motivación y actitud hacia el aprendizaje) tuvo un incremento no significativo (Sig. $=.580$ ). No obstante, puede apreciarse que, en el resto de las dimensiones, así como en el puntaje de autorregulación del aprendizaje (GAA), se observó diferencia significativa.

Respecto de los resultados generales podemos observar que en todos los casos, la diferencia de medias es estadísticamente significativa, teniendo así evidencia suficiente para rechazar la hipótesis nula inherente al problema de investigación y concluyendo 
que los estudiantes tuvieron un avance estadísticamente significativo en el grado de autorregulación del aprendizaje (y en cada uno de sus constructos constitutivos) a lo largo del ciclo escolar, independientemente del cambio de modalidad educativa producido por la contingencia sanitaria.

A fin de profundizar en los resultados, se realizó un análisis comparativo de las dimensiones (D1, D2 y D3) y el grado de autorregulación del aprendizaje (GAA), en función de la variable sexo. Para ello se utilizaron los datos de la segunda aplicación de la ESSA, empleando una prueba T para muestras independientes. En la tabla 12 se presentan los resultados.

Tabla 12. Prueba T para muestras independientes en función de la variable: sexo

\begin{tabular}{|c|c|c|c|c|}
\hline Aspecto & Media Mujeres & Media Varones & Sig. Levene & Sig. Prueba T \\
\hline D1 & 4.31 & 4.00 & $.001^{*}$ & .000 \\
\hline D2 & 4.11 & 3.89 & $.003^{*}$ & .001 \\
\hline D3 & 3.73 & 3.63 & .654 & .193 \\
\hline GAA & 4.05 & 3.83 & $.004^{*}$ & .001 \\
\hline
\end{tabular}

* La Prueba Levene en D1, D2 y GAA evidencia que no hay igual de varianzas. Para la Prueba T se ha considerado el valor de significancia, asumiendo varianzas distintas.

Se aprecia que existe diferencia estadísticamente significativa entre los puntajes de D1 (Motivación y actitud hacia el aprendizaje), D2 (Estrategias cognitivas) y GAA (Grado de Autorregulación del Aprendizaje) de los estudiantes en función del sexo, siendo mayor en los tres casos en las mujeres. Únicamente en la D3 (Autoevaluación y regulación metacognitiva) la diferencia observada no fue significativa. Por tanto, se tiene evidencia suficiente para asumir que las mujeres tienden a tener un mejor desarrollo que los varones en la autorregulación del aprendizaje y sus componentes constitutivos.

Con el grado de autorregulación del aprendizaje (GAA), observado en la segunda aplicación del instrumento, se decidió generar una nueva variable de escala nominal para categorizar a los estudiantes en cuatro subgrupos (Categorías de AA). Estos se definieron con rangos establecidos a través de los cuartiles, siendo los siguientes: a) insuficiente (0 a Q1=3.65); b) básico (3.651 a Q2=4); c) satisfactorio (4.01 a Q3=4.29), y d) estratégico (4.291 a 5). Se procedió entonces a revisar si existía dependencia entre esta variable y las de sexo y nivel educativo respectivamente, a través de las pruebas chi cuadrada de independencia y razón de verosimilitud. En la tabla 13 se presentan los resultados correspondientes. Cabe destacar que, aunque no se presentan, todos los valores esperados fueron mayores que 5, siendo así válida la aplicación de ambas pruebas. 
Tabla 13. Pruebas chi cuadrada de independencia y razón de verosimilitud

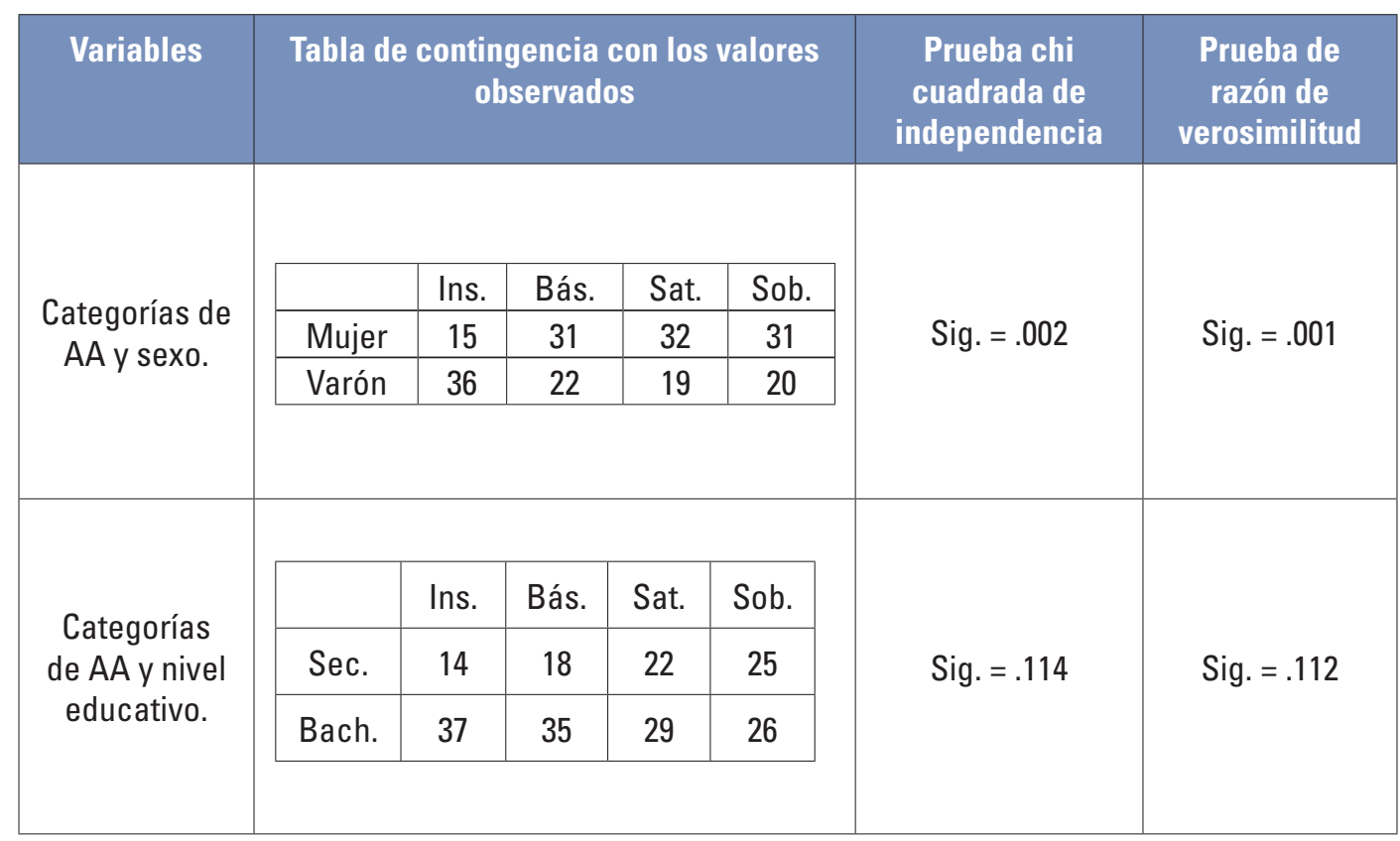

Se identifica que existe dependencia (Sig. $=.002$ y .001) entre las variables sexo y categorías de AA, siendo que ser mujer influye sobre el hecho de lograr posicionamiento en categorías superiores (satisfactorio y sobresaliente). Lo anterior coincide con la prueba $\mathrm{T}$ de muestras independientes presentada anteriormente, donde se encontró que había diferencia significativa en el grado de autorregulación del aprendizaje de los estudiantes en función del sexo, siendo mayor en mujeres.

En torno de las variables nivel educativo y categorías de AA, se observa independencia (Sig. = .114 y .112), por lo que el hecho de que ser estudiante de secundaria o bachillerato no influye respecto de la categoría de autorregulación del aprendizaje en la que se está posicionado, habiendo en ambos niveles educativos cantidades semejantes de estudiantes en los cuatro posibles niveles.

Al haber variación en los años de antigüedad de los estudiantes en el plantel educativo, se generó una matriz con coeficientes de correlación de Pearson entre dicha variable y D1, D2, DE y GAA. En la tabla 14 se presentan los resultados.

Tabla 14. Correlación de Pearson entre Años de Antigüedad y D1, D2, D3 y GAA

\begin{tabular}{|c|c|c|c|c|}
\hline & D1 & D2 & D3 & GAA \\
\hline $\begin{array}{c}\text { Años de } \\
\text { antigüedad }\end{array}$ & $\mathrm{r}=-.001$ & $\mathrm{r}=-.052$ & $\mathrm{r}=-.019$ & $\mathrm{r}=-.010$ \\
& Sig. (Bilat.) $=.991$ & Sig. (Bilat.) $=.440$ & Sig. (Bilat.) $=.776$ & Sig. (Bilat.) =.877 \\
\hline
\end{tabular}


Los valores cercanos a cero en los coeficientes, así como las significancias bilaterales mayores que 0.05 , brindan evidencia suficiente para concluir que no existe relación estadísticamente significativa entre los componentes y el puntaje de autorregulación del aprendizaje con la antigüedad en el centro escolar.

\section{DISCUSIÓN Y CONCLUSIONES}

Dentro del marco del enfoque centrado en competencias, las denominadas metodologías activas se revelan como medios efectivos para generar aprendizajes significativos y afrontar los retos desconocidos del futuro (Ruiz, 2017), ya que permiten poner en juego habilidades, capacidades, conocimientos y actitudes en situaciones dadas y contextos diversos (Pimienta, 2012). La aplicación de estas dentro de la era digital, ha provocado el fomento de la modalidad educativa a distancia, a través de la capitalización de recursos tecnológicos que permiten el diseño de ambientes híbridos o virtuales de aprendizaje. En este sentido, el e-learning se visibiliza con mayor énfasis cada vez, siendo un enfoque que frente al cierre indefinido de centros escolares por la pandemia de la COVID-19, ha sido aplicado por numerosas instituciones educativas.

Ante el súbito y forzoso cambio de modalidad que se enfrentó en los planteles educativos de México, surgieron legítimas dudas en investigadores, directivos y docentes respecto de los efectos implicados en el aprendizaje de los estudiantes. Este estudio se centró en una habilidad fundamental para el buen desempeño dentro del enfoque centrado en competencias: la autorregulación del aprendizaje. El análisis de resultados ha relevado que, pese al cambio de modalidad, los estudiantes de educación secundaria y media superior lograron un avance estadísticamente significativo en el desarrollo de dicha variable, conclusión que representa una fortaleza del estudio al brindar luz ante las dudas antes mencionadas. En este sentido, el haber mantenido vigente el enfoque por competencias, enfatizando la metodología activa del aprendizaje basado en proyectos, con trabajo colaborativo, y acciones de autoevaluación y metacognición implementadas a través del diseño gradual de un portafolios de evidencias del ciclo escolar por parte de cada estudiante, posibilitó que el grado de autorregulación del aprendizaje incrementara significativamente a lo largo del ciclo escolar.

Lo anterior se relaciona con investigaciones que documentan el alcance o impacto de la coyuntura social del COVID-19 en el ámbito educativo. En Latinoamérica existen poblaciones que presentan un limitado acceso a recursos electrónicos para el aprendizaje a distancia y una gran desinformación respecto del uso de las tecnologías; no obstante, las redes de apoyo de las escuelas y las comunidades de padres de familia han sido un recurso para enfrentar dichas limitaciones (Ramírez-Ramírez, Arvizu-Reynaga, Ibañez-Reyes, Claudio-Martínez y Ramírez-Arias, 2020).

Otra fortaleza del estudio radica en el instrumento diseñado para medir la variable de estudio, mismo que logra un nivel de validez adecuado. Además de la valía pedagógica del recurso, se reconoce una relevancia teórica, ya que contribuye con la sustentación científica de un enfoque educativo (centrado en el desarrollo de competencias) que ha sido operado a priori por exigencias internacionales de índole económico y político -como las inherentes al Program for International Student Assessment (PISA-OCDE) (Esparza, 2018) - y no como efecto del acercamiento teórico, filosófico y científico que caracterizó a sus enfoques antecesores. 
Una limitación del estudio radica en el hecho de que no se puede atribuir el incremento significativo de autorregulación del aprendizaje en los estudiantes a la modalidad online. Lo anterior se debe a que no se pudo tener control sobre otras co-variables potencialmente explicativas, como la maduración, la dinámica familiar, entre otras. No obstante, esto no resta validez ni relevancia a la conclusión, ya que las evidencias permiten suponer que el cambio de modalidad no representó obstáculo para un incremento significativo de la variable de estudio en los alumnos.

En cuanto al instrumento, se encontró que un reactivo (R3) no ajustó con su dimensión desde el análisis factorial exploratorio realizado, por lo que sería conveniente modificarlo o eliminarlo. Asimismo, se observaron tres reactivos con cargas factoriales considerables para más de una dimensión (R14, R15 y R19), mismos que convendría revisar y modificar para ajustarlos más con su respectiva dimensión. Estas limitaciones invitan a vislumbrar como escenario futuro, dentro de esta línea de investigación, la realización de un estudio orientado a una validación confirmatoria de la ESAA, contemplando una muestra representativa de mayor tamaño que permita un mayor nivel de generalización.

Otros escenarios de continuidad en investigación, radican en el diseño de estudios cuasiexperimentales que permitan identificar si distintas metodologías activas (aprendizaje basado en proyectos, estudio de caso, aprendizaje basado en problemas, simulaciones, entre otras), así como estrategias o recursos tecnológicos (STEAM, aulas Makerspace, realidad aumentada y realidad virtual), inciden sobre el desarrollo de la autorregulación del aprendizaje.

Otra línea de interés se orienta a una indagación a profundidad sobre los motivos por los que se identifica un grado de autorregulación significativamente mayor en estudiantes mujeres que en varones, hecho que ha sido observado en este estudio, pero que discrepa con lo identificado en contextos de educación superior de España (Chaves, Trujillo y López, 2016), donde no se observa una diferencia significativa en ambientes presenciales. En este sentido, valdría la pena indagar si la diferencia que hemos observado puede deberse a la modalidad online, o bien, a factores propios del contexto mexicano.

Dentro de un plano psicológico, se proyecta otra línea orientada al estudio de la correlación de la autorregulación del aprendizaje con la variable estrés académico, aspecto que ha sido abordado en el nivel medio superior de México en modalidad presencial, identificando correlación negativa estadísticamente significativa, entre el estrés y el rendimiento escolar (Fernández-de-Castro y Luévano, 2018). En este sentido, resulta de interés identificar si en la modalidad online dicha correlación permanece, así como posibles efectos con la autorregulación del aprendizaje.

\section{ANEXO A. INSTRUMENTO DE MEDICIÓN}

\section{Escala de Autorregulación en el Aprendizaje (ESAA)}

El presente instrumento pretende identificar aspectos relacionados con la autorregulación en el aprendizaje. Su aplicación se realiza para fines de investigación. Se solicita su valiosa colaboración, garantizando que los resultados serán en todo momento confidenciales. 


\section{Datos de identificación}

Escriba los datos solicitados en los recuadros correspondientes.

\begin{tabular}{|l|l|}
\hline Nombre completo & \\
\hline Grado que cursa & \\
\hline Edad (años cumplidos) & \\
\hline Años de antigüedad en el colegio & \\
\hline
\end{tabular}

\section{ESAA}

Se presentan a continuación una serie de factores sobre el proceso de aprendizaje. Usted deberá valorar qué tan de acuerdo está con la presencia de estos en su rol cotidiano como estudiante. Se solicita responder con honestidad, considerando que no hay respuesta buena o mala. Marque con una X su valoración considerando la escala que se presenta.

\begin{tabular}{|c|c|c|c|c|}
\hline $\mathbf{1}$ & $\mathbf{2}$ & $\mathbf{3}$ & $\mathbf{4}$ & $\mathbf{5}$ \\
\hline $\begin{array}{c}\text { Muy poco de } \\
\text { acuerdo. }\end{array}$ & $\begin{array}{c}\text { Poco } \\
\text { de acuerdo. }\end{array}$ & $\begin{array}{c}\text { Medianamente de } \\
\text { acuerdo. }\end{array}$ & $\begin{array}{c}\text { Bastante } \\
\text { de acuerdo. }\end{array}$ & $\begin{array}{c}\text { Totalmente de } \\
\text { acuerdo. }\end{array}$ \\
\hline
\end{tabular}

\begin{tabular}{|c|c|c|c|c|c|}
\hline Aspectos & 1 & 2 & 3 & 4 & 5 \\
\hline 1. Pienso que el aprendizaje es algo que me enriquece como persona. & & & & & \\
\hline 2. Me interesa construir aprendizajes para poder mejorar la sociedad. & & & & & \\
\hline $\begin{array}{l}\text { 3. Ante las materias que curso, me propongo metas de aprendizaje por interés } \\
\text { personal. }\end{array}$ & & & & & \\
\hline 4. Me interesa obtener buenas calificaciones en las materias que curso. & & & & & \\
\hline 5. Espero que mis padres y profesores reconozcan mi esfuerzo por aprender. & & & & & \\
\hline $\begin{array}{l}\text { 6. Trabajo con dedicación las tareas y actividades de clase, asignadas por mis } \\
\text { profesores. }\end{array}$ & & & & & \\
\hline 7. Me considero un estudiante al que se le facilita el aprendizaje. & & & & & \\
\hline $\begin{array}{l}\text { 8. Cuando mis profesores plantean trabajos y proyectos nuevos, me siento capaz } \\
\text { de desarrollarlos exitosamente. }\end{array}$ & & & & & \\
\hline 9. Considero que los éxitos académicos que he tenido se deben a mi esfuerzo. & & & & & \\
\hline $\begin{array}{l}\text { 10. Considero que los aprendizajes que he desarrollado se deben a mis cualidades } \\
\text { y habilidades personales. }\end{array}$ & & & & & \\
\hline $\begin{array}{l}\text { 11. Cuando se trabajan nuevos temas o proyectos en clase, suelo reflexionar sobre } \\
\text { los conocimientos previos que tengo al respecto. }\end{array}$ & & & & & \\
\hline
\end{tabular}




\begin{tabular}{|c|c|c|c|c|c|}
\hline Aspectos & 1 & 2 & 3 & 4 & 5 \\
\hline $\begin{array}{l}\text { 12. Normalmente relaciono los temas que se van a trabajar en clase con } \\
\text { experiencias o sucesos que he vivido en el pasado. }\end{array}$ & & & & & \\
\hline $\begin{array}{l}\text { 13. Antes de empezar un trabajo o proyecto, suelo tener claras las características } \\
\text { que este debe tener. }\end{array}$ & & & & & \\
\hline $\begin{array}{l}\text { 14. Identifico las expectativas de los profesores sobre los trabajos y proyectos que } \\
\text { asignan. }\end{array}$ & & & & & \\
\hline $\begin{array}{l}\text { 15. Antes de realizar un trabajo o proyecto, acostumbro a pensar en acciones que } \\
\text { hagan más fácil el cumplimiento exitoso de lo esperado. }\end{array}$ & & & & & \\
\hline $\begin{array}{l}\text { 16. Ante las actividades de clase, tareas y proyectos que mis profesores asignan, } \\
\text { hago primero un plan de acciones a desarrollar para, posteriormente, aplicarlo. }\end{array}$ & & & & & \\
\hline $\begin{array}{l}\text { 17. Cuando los trabajos son en equipo, me gusta fomentar que los integrantes nos } \\
\text { pongamos de acuerdo en los pasos que se van a seguir, para luego desarrollarlos. }\end{array}$ & & & & & \\
\hline $\begin{array}{l}\text { 18. Suelo pedir ayuda a mis profesores cuando no entiendo algún tema o alguna } \\
\text { actividad de clase. }\end{array}$ & & & & & \\
\hline $\begin{array}{l}\text { 19. Cuando mis profesores dan explicaciones sobre un tema o actividad, suelo } \\
\text { poner atención. }\end{array}$ & & & & & \\
\hline $\begin{array}{l}\text { 20. Pido ayuda a mis compañeros cuando no entiendo algún tema o alguna actividad } \\
\text { de clase. }\end{array}$ & & & & & \\
\hline $\begin{array}{l}\text { 21. Aprovecho las explicaciones que mis compañeros puedan brindarme sobre los } \\
\text { temas o las actividades de clase. }\end{array}$ & & & & & \\
\hline $\begin{array}{l}\text { 22. Cuando trabajo alguna actividad de aprendizaje en clase o casa, me siento con } \\
\text { la confianza de estar haciendo las cosas de modo correcto. }\end{array}$ & & & & & \\
\hline $\begin{array}{l}\text { 23. Tomo decisiones con seguridad ante las dudas que surgen en las tareas, los } \\
\text { trabajos y proyectos que asignan mis profesores. }\end{array}$ & & & & & \\
\hline $\begin{array}{l}\text { 24. Suelo contar con útiles y recursos escolares suficientes para aprovechar al } \\
\text { máximo las clases (libros, cuadernos, plumas, lápices, calculadora, regla, etcétera). }\end{array}$ & & & & & \\
\hline $\begin{array}{l}\text { 25. Utilizo equipo tecnológico conveniente para la realización de tareas, trabajos y } \\
\text { proyectos (laptop, tableta, smartphone, acceso a Internet, etcétera). }\end{array}$ & & & & & \\
\hline $\begin{array}{l}\text { 26. Suelo aprovechar de modo eficiente el tiempo que se me brinda para desarrollar } \\
\text { los trabajos de clase. }\end{array}$ & & & & & \\
\hline $\begin{array}{l}\text { 27. Cuando desarrollo trabajos y proyectos, suelo darme cuenta de los obstáculos } \\
\text { que surgen y pueden dificultar mi aprendizaje. }\end{array}$ & & & & & \\
\hline $\begin{array}{l}\text { 28. Encuentro modos eficientes de superar las dificultades que surgen al momento } \\
\text { de realizar actividades de clase y tareas. }\end{array}$ & & & & & \\
\hline $\begin{array}{l}\text { 29. Me considero un estudiante que enfrenta las cuestiones académicas con } \\
\text { tranquilidad y sin estresarse. }\end{array}$ & & & & & \\
\hline $\begin{array}{l}\text { 30. Ante las actividades de aprendizaje difíciles o cuando hay mucha carga } \\
\text { académica, suelo mantenerme con tranquilidad. }\end{array}$ & & & & & \\
\hline $\begin{array}{l}\text { 31. Normalmente me doy cuenta de los aprendizajes que estoy generando a lo } \\
\text { largo del desarrollo de un proyecto o una actividad de clase. }\end{array}$ & & & & & \\
\hline
\end{tabular}




\begin{tabular}{|c|c|c|c|c|c|}
\hline Aspectos & 1 & 2 & 3 & 4 & 5 \\
\hline $\begin{array}{l}\text { 32. Realizo reflexiones sobre mi forma de trabajar que me permiten hacer cambios } \\
\text { o ajustes para favorecer mi desempeño y aprendizaje. }\end{array}$ & & & & & \\
\hline $\begin{array}{l}\text { 33. Acostumbro a revisar la calidad de mis trabajos y proyectos durante el proceso } \\
\text { de desarrollo de los mismos. }\end{array}$ & & & & & \\
\hline $\begin{array}{l}\text { 34. Al finalizar una tarea, un trabajo o proyecto hago una autoevaluación objetiva } \\
\text { del mismo, identificando fortalezas y áreas de mejora. }\end{array}$ & & & & & \\
\hline $\begin{array}{l}\text { 35. Identifico con claridad las limitaciones personales que tengo ante ciertos } \\
\text { temas, materias o tipos de actividades académicas. }\end{array}$ & & & & & \\
\hline $\begin{array}{l}\text { 36. Busco apoyo, estrategias y otros mecanismos para superar mis limitaciones } \\
\text { personales, a fin de favorecer mi desempeño académico y aprendizaje. }\end{array}$ & & & & & \\
\hline $\begin{array}{l}\text { 37. Evito los factores de distracción que hay en mi casa al momento de estudiar o } \\
\text { realizar tareas. }\end{array}$ & & & & & \\
\hline $\begin{array}{l}\text { 38. Evito los factores de distracción que hay en el colegio al momento de recibir } \\
\text { clases o realizar actividades académicas. }\end{array}$ & & & & & \\
\hline $\begin{array}{l}\text { 39. Cada vez que finalizo un trabajo de clase o proyecto, visualizo aspectos en los } \\
\text { que puedo mejorar como estudiante para lograr un mejor desempeño. }\end{array}$ & & & & & \\
\hline $\begin{array}{l}\text { 40. Considero que después de cada parcial o período, me convierto en un mejor } \\
\text { estudiante. }\end{array}$ & & & & & \\
\hline
\end{tabular}

Por favor revise que haya contestado todos los reactivos.

¡Muchas gracias por su colaboración!

\section{REFERENCIAS}

Akoglu, H. (2018). «User's guide to correlation coefficients». Turkish Journal of Emergency Medicine, 18, 91-93. doi: 10.1016/j.tjem.2018.08.001

Balcikanli, C. (2011). «Metacognitive Awareness Inventory for Teachers (MAIT)». Journal of Research in Educational Psychology, 9(3), 1309-1332. Recuperado de http://web.a.ebscohost.com/ehost/pdfviewer/pdfviewer?vid=4\&si$\underline{\mathrm{d}=5 \mathrm{a} 1119 \mathrm{f} 4-7 \mathrm{de} 8-469 \mathrm{c}-\mathrm{b} 5 \mathrm{ea}-8554 \mathrm{f} 3 \mathrm{df} 26 \mathrm{ee} \% 40 \text { sessionmgr4008 }}$

Bandura, A. (1977). «Self-efficacy: toward a unifying theory of behavioral change». Psychological review, 84(2), 191.

Barnard, L., Lan, W.Y., To, Y.M., Paton, V.O. \& Lai Shu-Ling (2008). «Measuring self-regulation in online and blended learning environments». The Internet and Higher Education, 12(1), 1-6. doi: 10.1016/j.iheduc.2008.10.005 
Barrera, L., Carrillo, G.M., Chaparro, L., Sánchez, B., Vargas, E. y Carreño, S.P. (2015). «Validez de constructo y confiabilidad del instrumento calidad de vida versión familiar en español». Revista Electrónica Trimestral de Enfermería, 37, 227-238, doi: 10.6018/ eglobal.14.1.185111

Chaves, E., Trujillo, J.M. y López, J.A. (2016). «Acciones para la autorregulación del aprendizaje en entornos personales». Revista de Medios y Educación, 48, 67-82. doi: $10.12795 /$ pixelbit.2016.i48.05

Cleary, T. J. (2006). «The development and validation of the Self-Regulation Strategy Inventory-Self-Report». Journal of School Psychology, 44, 307-322. doi: 10.1016/j. jsp.2006.05.002

Duchovicova, J. \& Dominika, H. (2019). «Self-Regulation of Pedagogy Students». New Perspectives in Science Education Conference Proceedings, 119-124. Slovakia.

Esparza, G. (2018). «El humanismo del nuevo modelo educativo, ¿reforma políticoeconómica o acción educativa?». En R.A. González (Ed.), Educación y humanismo. La filosofía de la educación frente a la crisis del hombre contemporáneo, 57-84. México: Juan Pablos Editor.

Esteve, J.M. (2003). «La formación del profesorado para una educación intercultural». Bordón, 56(1), 95-115.

Fernández-de-Castro, J. y Luévano, E. (2018). «Influencia del estrés académico sobre el rendimiento escolar en educación media superior». Revista Panamericana de Pedagogía, 26, 97-117. Recuperado de http://portalderevistasdelaup.mx/revistapedagogia/ index.php/pedagogia/article/view/284

Fernández, E., Bernardo, A., Suárez, N., Cerezo, R., Núñez, J.C. y Rosário, P. (2013). «Predicción del uso de estrategias de autorregulación en educación superior». Anales de Psicología, 29(3), 865-875. doi: 10.6018/ analesps.29.3.139341

Hernández, R., Fernández, C. y Baptista, P. (2014). Metodología de la Investigación. México: McGraw-Hill.

Jaramillo, S. y Osses, S. (2012). «Validación de un instrumento sobre metacognición para estudiantes de segundo ciclo de educación general básica». Estudios Pedagógicos, 38(2), 117-131. doi: 10.4067/S0718-07052012000200008

Kaplan, J., Montalembert, M., Laurent, P. y Fenouillet (2017). European Review of Applied Psychology, 67(2), 79-89. doi: 10.1016/j.erap.2017.01.001

López, O., Hederich-Martínez, C. y Camargo Á. (2012). «Logro en matemáticas, autorregulación del aprendizaje y estilo cognitivo». Suma Psicológica, 19(2), 39-50. Recuperado de http:/ / web.b.ebscohost.com/ehost/pdfviewer/pdfviewer?vid=8\&sid=57d5 51e3-9d89-45e4-a8ea-8a3c19673612\%40pdc-v-sessmgr01

Masciotra, D., Jonnaert, P. et Daviau, C. (2004). «La compétence revisitée dans une perspective située». Revue canadienne d'éducation, 1-7.

Masciotra, D., Roth, W.-M. \& Morel, D. (2007). Énaction Apprendre et enseigner en situation. 
Midgley, C., Maehr, M.L., Hruda, L.Z., Freeman, K.E., Gheen, M., Kaplan, A., Kumar, R., Middleton, M.J., Nelson, J., Roeser, R. \& Urdan, T. (2000). Manual for the patterns of adaptative learning scales. University of Michigan. Recuperado de https:/ / www.researchgate. net/publication/272474856 The Patterns of Adaptive Learning Scales PALS 2000

Muchiut, A.F., Zapata, R.B., Comba, A., Mari, M., Torres, N., Pellizardi, J. y Segovia A.P. (2008). «Neurodidáctica y autorregulación del aprendizaje, un camino de la teoría a la práctica». Revista Iberoamericana de Educación, 78(1), 205-219. doi: 10.35362/ rie7813193

Nunnally, J. C. \& Bernstein, I. H. (1994). Psychometric theory (3rd ed.). New York: McGraw-Hill.

Núñez, J.C., Amieiro, N., Álvarez, D., García, T. y Dobarro, A. (2015). «Escala de evaluación de la autorregulación del aprendizaje a partir de textos (ARATEX-R)». European Journal of Education and Psychology, 8(1), 9-22. doi: 10.1016/j.ejeps.2015.10.002

Organización de las Naciones Unidas en México (2020). Acerca del virus. Recuperado de https://coronavirus.onu.org. $\mathrm{mx} /$ coronavirus/acerca-del-virus

Organización Mundial de la Salud (2020). COVID-19: cronología de la actuación de la OMS. Recuperado de https://www.who.int/es/news-room/detail/27-04-2020-who$\underline{\text { timeline---covid-19 }}$

Pacheco-Rocha, L.E. (2014, septiembre, 7). Definición de competencia-Laura Frade. [Video]. Youtube. Recuperado de https: / youtu.be/WvumJRgtFpU

Peñalosa, E., Landa, P. y Vega C.Z. (2006). Aprendizaje autorregulado: una revisión conceptual.

Perrenoud, P. (2008). «Diez nuevas competencias para enseñar». Tiempo de Educar, 9(17), 159.

Perrenoud, P. (2009). «Enfoque por competencias, ¿una respuesta al fracaso escolar?». Revista Interuniversitaria de Pedagogía Social, 16, 45-64.

Pimienta, J.H. (2012). Estrategias de enseñanza-aprendizaje. México: Pearson Educación.

Pintrich, P.R. \& De Groot, E.V. (1990). «Motivational and self-regulated learning components of classroom academic performance». Journal of Educational Psychology, 82(1), 3340. Recuperado de http://web.stanford.edu/dept/SUSE/projects/ireport/articles/ self-regulation/self-regulated\%20learning-motivation.pdf

Ramírez-Ramírez, L. N., Arvizu-Reynaga, V., Ibañez-Reyes, L., Claudio-Martínez, C. y Ramírez-Arias, V. (2020). «Apoyo ante COVID-19 en Latinoamérica: Estudio exploratorio de las necesidades psico-socio educativas durante la contingencia». Covid-19. Consecuencias Psicológicas, Sociales, Politicas y Económicas, 1-22. España, Málaga: EUMED. Recuperado de: https:// www.eumed.net/actas/20/covid/8-apoyo-ante-covid-19-en-latinoamerica-estudio-exploratorio-de-las-necesidades.pdf

Ruiz, F. (2017). Diseño de proyectos STEAM a partir del currículum actual de Ed. Primaria utilizando Aprendizaje Basado en Problemas, Aprendizaje cooperativo, Flipped Classroom y Robótica Education. Tesis Doctoral. Valencia: Universidad CEU Cardenal Herrera.

Schraw, G. \& Dennison, R.S. (1994). «Assessing Metacognitive Awareness». Contemporary Educational Psychology, 19, 460-475. Recuperado de http://wiki.biologyscholars. org/@api/deki/files/99/=Schraw1994.pdf 
Secretaría de Gobernación (2020). Diario Oficial de la Federación. Acuerdo número 02/03/2020. Recuperado de https://www.dof.gob.mx/nota detalle.php?codigo $=5589479 \&$ fecha $=16 / 03 / 2020$

UNESCO (1998). Documento de Política para el cambio y el desarrollo en la Educación Superior. París: UNESCO.

Universidad Internacional de Valencia (2018). Aprender a aprender: una competencia básica para el aprendizaje permanente. Recuperado de https://www.universidadviu.es/aprender-a-aprender-una-competencia-basica-para-el-aprendizaje-permanente/

Vives-Varela, T., Duran-Cárdenas, C., Varela-Ruíz, M., y Fortoul T. (2014). «La autorregulación en el aprendizaje, la luz de un faro en el mar». Investigación en Educación Médica, 3(9), 34-39. Recuperado de http://riem.facmed.unam.mx/sites/all/archivos/ V3Num01/06 AR LA AUTORREGULACION.pdf

Yarnall, L., Freed, M., \& Malone, N. (2019). «Self-Regulated Learning». En Modernizing Learning: Building the future learning ecosystem, 285-297. E.U.A.: Government Publishing Office.

Zimmerman, B. J. (1995). «Self-regulation involves more than metacognition: A social cognitive perspective». Educational Psychologist, 30(4), 217-221.

Zimmerman, B. J. (1998). Developing self-fulfilling cycles of academic regulation: An analysis of exemplary instructional models. In D. H. Schunk \& B. J. Zimmerman (Eds.), Self-regulated learning: From teaching to self-reflective practice, 1-19. Guilford Publications.

Zimmerman, B. J., \& Schunk, D. H. (2011). Handbook of self-regulation of learning and performance. Routledge/Taylor \& Francis Group. 